\title{
Using residual analysis, auto- and cross-correlations to identify key processes for the calibration of the SWAT model in a data scarce region
}

\author{
K. Bieger, G. Hörmann, and N. Fohrer \\ Department of Hydrology and Water Resources Management, Institute for Natural Resource Conservation, University of Kiel, \\ Olshausenstr. 75, 24118 Kiel, Germany
}

Correspondence to: K. Bieger (kbieger@hydrology.uni-kiel.de)

\begin{abstract}
Hydrological modeling poses a particular challenge in data scarce regions, which are often subject to dynamic change and thus of specific interest to hydrological modeling studies. When a small amount of data available for a catchment is opposed by extensive data requirements by the chosen hydrologic model, ways have to be found to extract as much information from the available data as possible.

In a study conducted in the Xiangxi Catchment in the Three Gorges Region in China, the use of residual analysis as well as auto- and cross-correlations for enhanced model evaluation and for the identification of key processes governing the hydrological behavior of the catchment prior to model calibration was tested. The residuals were plotted versus various variables such as time, discharge and precipitation. Also, auto-correlations were calculated for measured and simulated discharge and cross-correlations of measured and simulated discharge with precipitation were analyzed. Results show that the analysis of residuals as well as auto- and cross-correlations can provide valuable information about the catchment response to rainfall events, which can be very helpful for calibration of hydrologic models in data scarce regions.
\end{abstract}

\section{Introduction}

In many parts of the world, parameterization and calibration of hydrological models is hampered by a lack of adequate input data (Zhao et al., 2011). But often it is especially those parts of the world, where dynamic change is currently encountered or expected to happen in the future and where modeling studies estimating the impacts of this change on hydrology and water quality are thus indispensable. There- fore, strategies have to be developed to exploit as much information from the available data as possible and find an efficient approach to model parameterization and calibration in data scarce regions (Sivapalan et al., 2003). Often the majority of parameters for complex models have to be roughly estimated (Hörmann et al., 2009). The discrepancy between the low amount of available data on the one hand and the high number of input variables required by many hydrologic models has to be overcome.

The Three Gorges Region in China is an area which is currently facing a large-scale land use change due to the construction of the Three Gorges Dam and the reservoir impoundment. In the Sino-German Yangtze Project (funded by the German Ministry of Education and Research) different aspects of this land use change and its impact on soil erosion, mass movements and diffuse inputs are assessed (Subklew et al., 2010). The chosen study area is the $3099 \mathrm{~km}^{2}$ large Xiangxi Catchment. The impact of land use change on the water balance as well as the sediment and phosphorus transport is assessed using the eco-hydrological model SWAT (Arnold et al., 1998). SWAT will be used during further progress of the project to simulate the impact of past, present and future land use patterns on the water balance as well as sediment and phosphorus transport in the catchment. But first of all, the model has to be calibrated in order to represent the hydrology of the Xiangxi Catchment, which is the driving force behind all other processes happening in the watershed. The calibration is hampered by the small amount of data and information available for the Xiangxi Catchment.

Hydrological modeling usually follows a typical workflow. First of all, the model is parameterized using the data available for the respective study area. Second, a sensitivity analysis is carried out to identify the most important model 
parameters to focus on during calibration and finally, the model is calibrated either manually or using an automated calibration procedure, which has been very popular in recent years (Abbaspour et al., 2007; Bekele and Nicklow, 2007; Eckhardt and Arnold, 2001; Eckhardt et al., 2005; Green and van Griensven, 2008; Muleta and Nicklow, 2005; Schuol and Abbaspour, 2006; Van Griensven and Meixner, 2007; Zhang et al., 2009). Model evaluation is mostly done by analyzing the simulated versus the measured hydrograph and by using statistical criteria like the Nash-Sutcliffe efficiency (NSE) or the coefficient of determination $\left(R^{2}\right)$.

Another option for model evaluation is residual analysis. This does not only evaluate model performance, but can also help to identify key processes, which govern the catchment response to rainfall events. So far, in the context of hydrological modeling residual analysis has only been used for model evaluation by very few authors (Aitken, 1973; Vandewiele et al., 1992; Xu, 2001; Feaster et al., 2010). Residuals as well as auto- and cross-correlations are used in this study to identify key processes governing the discharge in the study area prior to model calibration. The main objective is to test whether the analysis of residuals as well as auto- and cross-correlations can be used to support model calibration by allowing conclusions to be drawn with respect to key processes governing catchment behavior.

\section{Materials and methods}

\subsection{Study area}

The Xiangxi Catchment is located in the northwest of Hubei Province in Central China. It covers part of the counties Shennongjia, Xingshan, and Zigui and comprises an area of $3099 \mathrm{~km}^{2}$. Originating from the Shennongjia Mountain Nature Reserve in the northwest of the catchment, the Xiangxi River flows in a southward direction over a distance of $94 \mathrm{~km}$ until it discharges into the Yangtze River approximately $38 \mathrm{~km}$ upstream of the Three Gorges Dam. There are two significant tributaries of the Xiangxi River, the Gufu and the Gaolan Rivers (Fig. 1).

The Xiangxi Catchment is characterized by large differences in elevation of more than $3000 \mathrm{~m}$ and very steep slopes. The dominating soil types according to Chinese soil classification are Limestone soils and Yellow brown soils, but there are also large areas of Brown soils and Dark brown soils in the high mountain areas and of Purple soils and Yellow soils in the central and southern parts of the catchment. Land use is dominated by forest. Considerable areas of agricultural use can be found in the southern part of the catchment as well as along the rivers and major roads. The mean annual discharge at Gauge Xingshan amounts to $65.5 \mathrm{~m}^{3} \mathrm{~s}^{-1}$. The hydrograph of Xiangxi River shows a strong seasonality with high discharge during the summer monsoon and low discharge in winter.

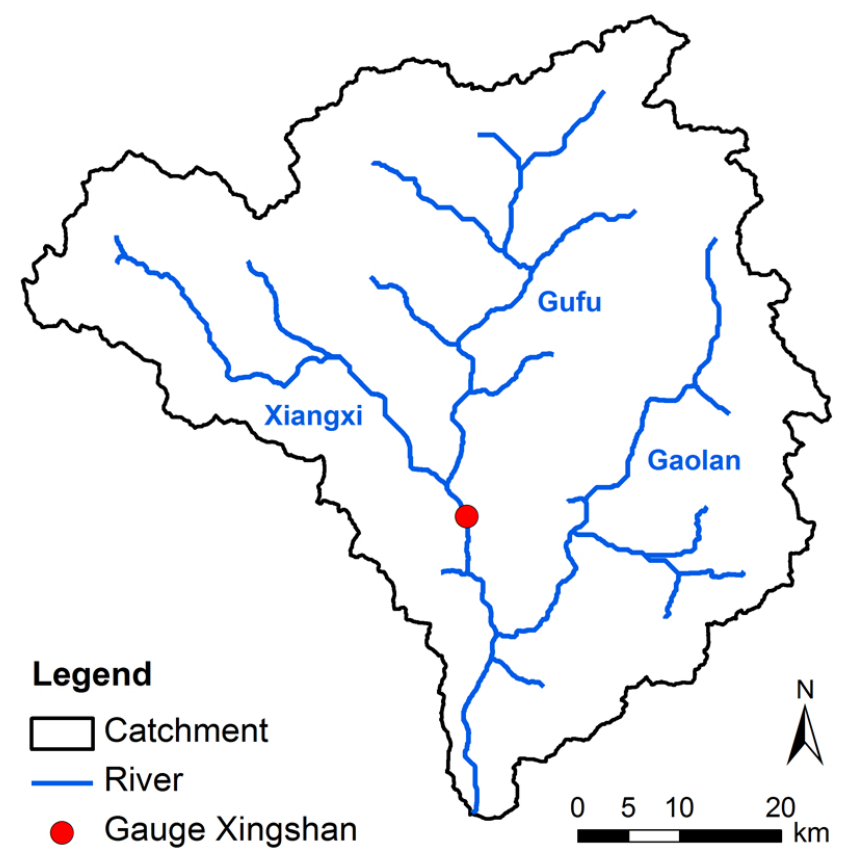

Fig. 1. The Xiangxi Catchment with the location of Gauge Xingshan.

\subsection{The SWAT model}

SWAT (Soil and Water Assessment Tool; Arnold et al., 1998) is an eco-hydrological model, which was developed for modeling the effect of changes in land use and management on the water balance as well as the transport of sediment and agricultural chemicals. It is a continuous time model designed for simulating long periods of time. SWAT has been applied to various catchments all over the world (Arnold and Fohrer, 2005; Gassman et al., 2007) and has proven to be a capable tool for assessing the impact of land use changes on water quantity and quality (Behera and Panda, 2006; Cao et al., 2009; Chaplot et al., 2004; Fohrer et al, 2002; Fohrer et al., 2005; Guo et al., 2008; Heuvelmans et al., 2004; Huisman et al., 2004; Jha et al., 2010; Lenhart et al., 2003; Mishra et al., 2007).

In SWAT, the catchment is divided into subbasins, which are then further subdivided into hydrologic response units (HRU). An HRU is defined by a unique combination of land use, soil, and slope, so it is not identified spatially, but rather a lumped area of all areas with the same combination of land use, soil, and slope (Neitsch et al., 2010).

Simulation of the hydrologic cycle is separated into a land phase and a water phase (Neitsch et al., 2005). The simulation of the land phase is based on the water balance equation, which is calculated separately for each HRU. Moisture and energy inputs needed to drive the hydrologic cycle are provided by the climatic variables precipitation, maximum and minimum temperature, solar radiation, wind speed and relative humidity. These can be input from measured time series 
or simulated by the weather generator. Processes taken into account in a HRU include interception, evapotranspiration, infiltration, water movement in the soil profile and runoff. Water can be stored within an HRU in a deep and a shallow aquifer, in the soil profile and in the form of snow. Runoff generated in the HRUs is summed up to calculate the amount of water reaching the main channel in each subbasin (Neitsch et al., 2005). The water phase of the hydrologic cycle describes the routing of runoff in the river channel, using either a variable storage coefficient method (Williams, 1969) or the Muskingum routing method.

SWAT allows for detailed management schemes to be defined for each HRU, including time of planting and harvesting, time and amount of fertilizer and pesticides applications, irrigation and grazing. In SWAT2009, the current version of the model, a land use update module was integrated as a new feature to simulate land use change in the subbasins.

\subsection{SWAT model setup}

For this study, SWAT is used in the current version SWAT2009. To set up SWAT for a catchment, the model requires a digital elevation model, a soil map and a land use map as well as climatic data.

The required spatial data was mostly provided by the project partners of the YANGTZE-Project. The Digital Elevation Model (DEM) was downloaded from the SRTM database (Jarvis et al., 2008), where it is available with a resolution of $90 \mathrm{~m} \times 90 \mathrm{~m}$. The soil map was digitized from analogue soil maps of the counties Shennongiia, Xingshan and Zigui on a scale of 1:160000/1:180000, which were mapped during the Second National Soil Survey in China (Schönbrodt et al., 2012). The corresponding soil parameters of the soil types occurring in the Xiangxi Catchment were obtained from internet and literature resources (China Scientific Soil Database, 2010; Guo et al., 2008; Schönbrodt et al., 2010). A total of three land use maps classified from Landsat images is available for the years 1987, 1999 and 2007 (Seeber et al., 2010).

One climate station located within (Xingshan) and two climate stations located just outside the catchment (Shennongjia and Zigui) are implemented in the model. For all three stations long-term records are available for precipitation, temperature, humidity and wind speed. Solar radiation was calculated from sunshine duration. The statistics used by the weather generator to simulate missing climate data were calculated using the time series of station Xingshan.

The model is run on a daily time step for the years 1985 to 1993, but only the last six years are used for calibration, while the first three years are used as warm-up period. SWAT has not been calibrated for the Xiangxi Catchment yet. The data used for this study are the results of the initial SWAT model run.

\subsection{Model evaluation}

Most commonly, evaluation of hydrologic models is done by comparing the simulated and the measured hydrographs or flow duration curves graphically and using one or more statistical criteria, e.g. the NSE (Nash-Sutcliffe efficiency; Nash and Sutcliffe, 1970), the PBIAS (Percent bias; Gupta et al., 1999) or the RSR (RMSE-observations standard deviation ratio). The statistical criteria give an overall performance rating for the simulation, but all information on the characteristics of the hydrograph is lost due to evaluating the whole time series using just one single value.

Residuals are the differences between the measured and simulated values. This means that negative residuals indicate an overestimation of discharge by the model, while positive residuals indicate an underestimation. Residuals can be analyzed without losing the time reference of the data, which allows for the consideration of seasonal effects. Also, it is possible to examine specific parts of the hydrograph separately, like for example the rising limb and the recession curve or high and low flows. In spite of the diverse possibilities offered for model evaluation by residual analysis, it is not very commonly used in hydrological modeling. Nevertheless, residual analysis has been included in model evaluation by a few authors (Aitken, 1973; Vandewiele et al., 1992; $\mathrm{Xu}, 2001$; Feaster et al., 2010). In this study, residual analysis is not used to check whether the residuals behave as required by the model hypotheses, but it is rather used as a tool to get as much information out of the available data as possible before starting to calibrate the model. Therefore, the residuals are plotted versus different important variables like time, runoff and precipitation. Also, the auto-correlations of measured and simulated discharge and the cross-correlations of measured and simulated discharge with precipitation are calculated and analyzed in order to identify possible shortcomings in the representation of runoff processes in the model.

\section{Results and discussion}

\subsection{Common model evaluation}

The hydrograph and the statistical criteria give a good idea of the overall model performance. The hydrograph indicates that the simulated discharge fits the measured discharge reasonably well (Fig. 2). This is also confirmed by the NashSutcliffe efficiency, the PBIAS, and the $R^{2}$, which are 0.42 , 42.1 , and 0.63 , respectively. Even though the statistical criteria are not in the range considered as satisfactory by Moriasi et al. (2007), they are quite satisfactory when taking into account that the model has not been calibrated yet. Nevertheless, there is definitely room and need for improvement of the simulated hydrograph. 


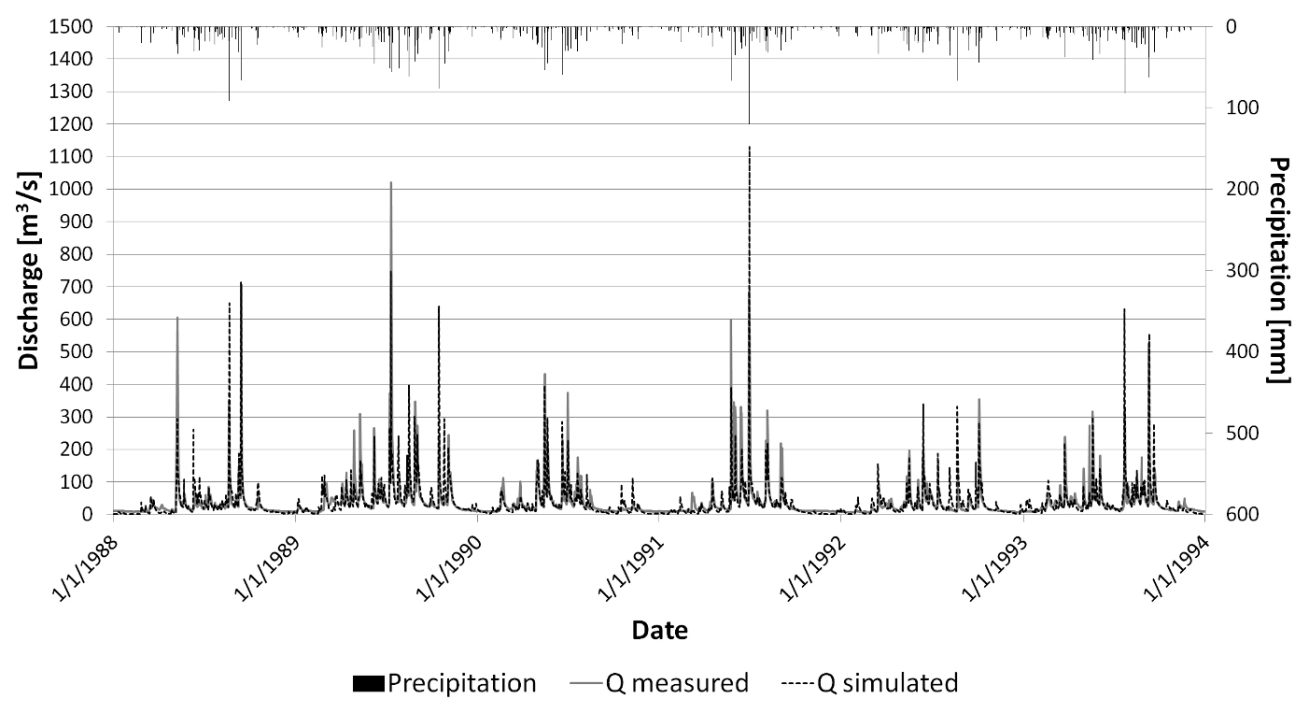

Fig. 2. Time series of measured versus simulated discharges at gauge Xingshan during the calibration period.

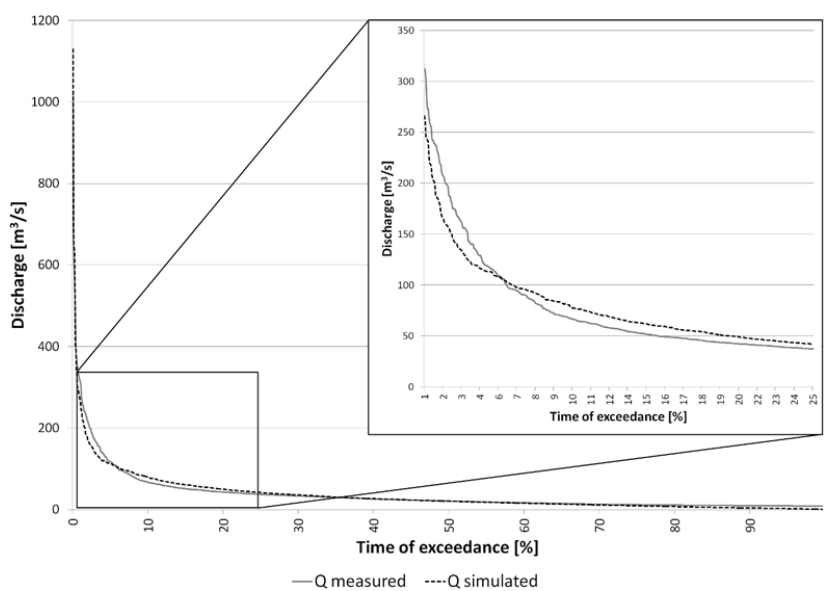

Fig. 3. Flow duration curves for measured and simulated discharges at gauge Xingshan during the calibration period.

The flow duration curve (Fig. 3) shows that discharge which is exceeded up to $0.5 \%$ and between 5.5 and $25 \%$ of the time is slightly overestimated by the model, whereas discharge which is exceeded 0.5 to $5.5 \%$ and more than $70 \%$ of the time is slightly underestimated. The flow duration curve gives some valuable information which is not as obvious from the hydrographs (Fig. 2) and which is not given by the statistical criteria. But still it is not possible to draw any conclusions with regard to the processes responsible for the differences between measured and simulated discharge. The analysis of residuals as well as auto- and cross-correlations can be used in this context to extend model evaluation and at the same time it can provide hints how to improve the parameterization of the model.

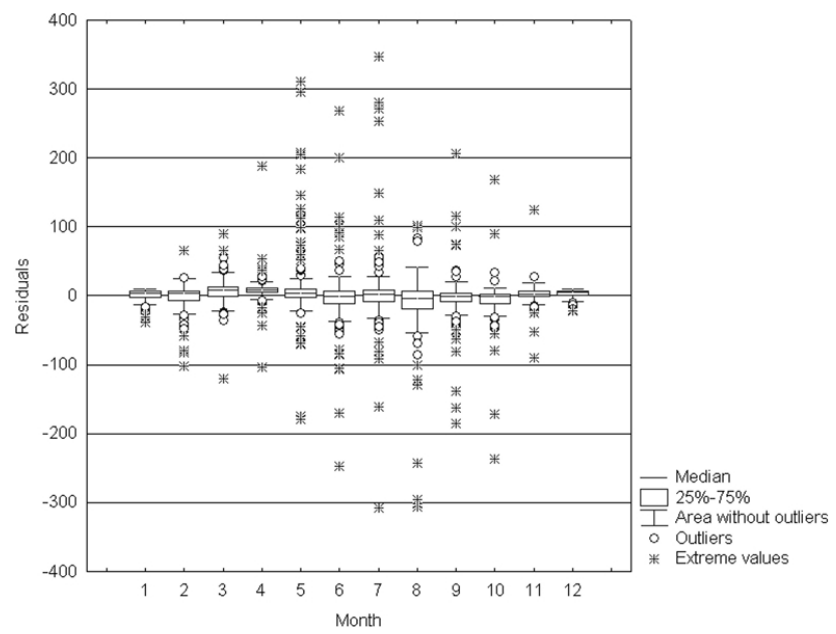

Fig. 4. Box-and-Whisker plot for residuals per month.

\subsection{Residual analysis}

The six-year calibration period comprises a total of 2192 days. Discharge is overestimated by the model on 829 days as indicated by the negative residuals and underestimated on 1362 days as indicated by the positive residuals.

Figure 4 shows that there is some seasonality in the residuals. The largest residuals occur in summer. This can be explained by the influence of the summer monsoon, which brings about frequent and heavy precipitation events and accordingly high discharges. The residuals indicate that the peaks are not simulated very well by the model yet. Nevertheless, there is no clear trend towards positive or negative values, which indicates that some model variable causes it to overestimate discharge in certain situations and to underestimate it in others. Here a more detailed analysis of processes 


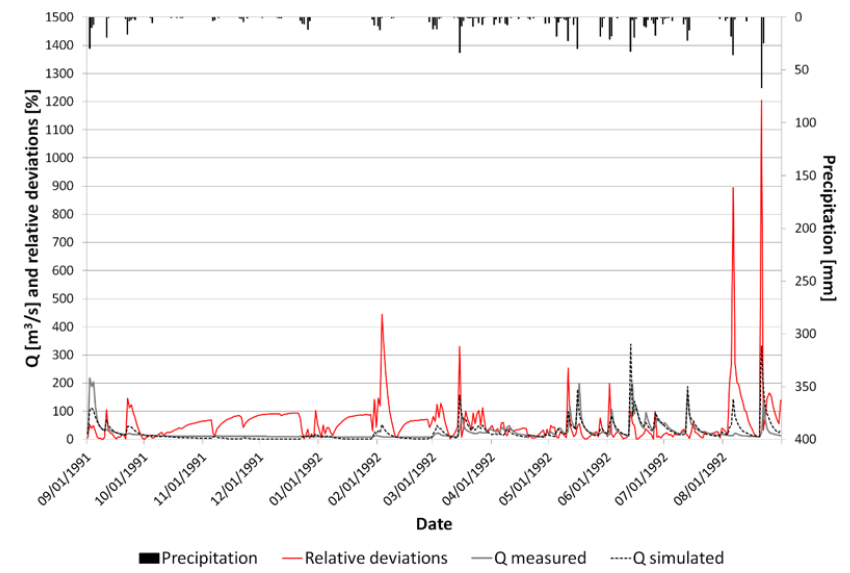

Fig. 5. Relative deviations of simulated discharge from measured discharge $(\%)$, Measured and simulated discharge $\left(\mathrm{m}^{3} \mathrm{~s}^{-1}\right)$ and precipitation (mm) during the time period from 1 September 1991 to 31 August 1992.

will be required in order to identify the factors governing the formation of high discharges. Both positive and negative outliers and extreme values are visible. Also, the range without outliers is quite large in summer while it is much smaller during the low flow period in winter, when residuals are lower and mostly tend towards slightly positive values. It is important to keep in mind that low absolute residuals might still be very high when related to the measured discharge. Therefore the simulated data might not fit the measured data very well during low flow periods even though the comparatively small residuals suggest the opposite.

The relative deviations plotted in Fig. 5 reveal that the largest relative differences between measured and simulated discharge occur during smaller floods events, especially following a low flow period. In certain cases, the simulated discharge reacts to precipitation events while there is no change in the observed discharge, while in other cases, there is a timing error and the simulated peak occurs one or two days earlier than the observed peak. This suggests that the variability of precipitation in the Xiangxi Catchment is not represented very well by the available climate data. In SWAT, each subbasin is assigned the precipitation data measured at the climate station closest to its center. Therefore, the data measured at climate station Xingshan is assumed to be valid for large parts of the catchment and local rainfall events can have a much higher impact on simulated discharge than they had on discharge in reality. This stresses the importance of representative climate data, especially in mountainous catchments.

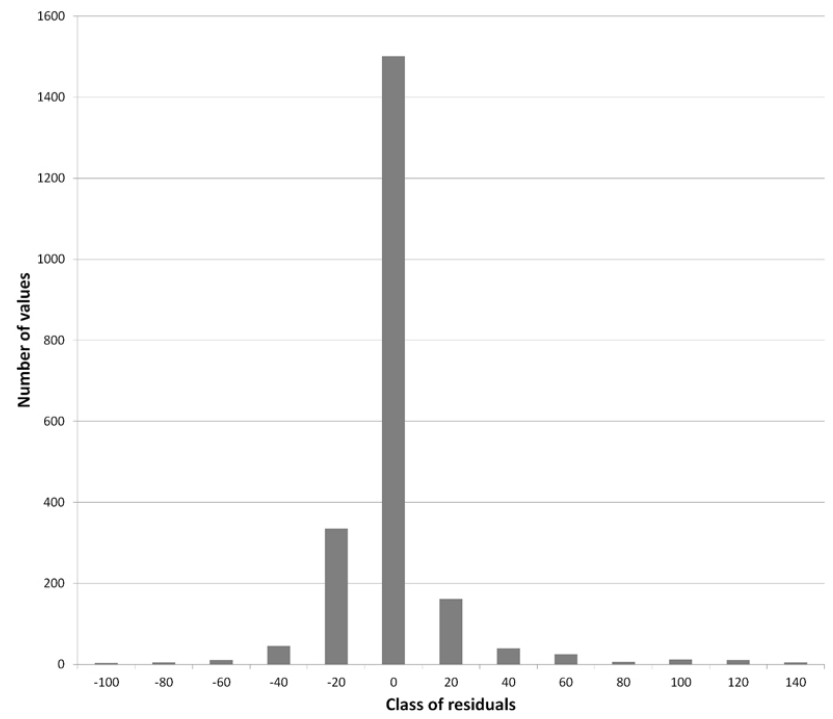

Fig. 6. Number of values in each class of residuals (classes named according to their lower boundary).

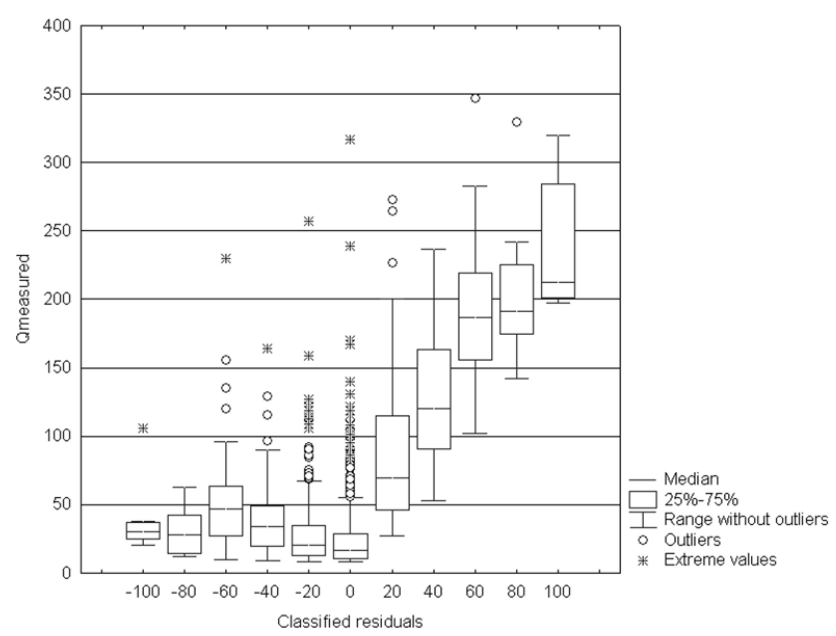

Fig. 7. Box-and-Whisker plot for measured discharge versus classified residuals (classes named according to their lower boundary).

The relative deviations tend to increase during the low flow period in winter, which is due to a slow decrease of simulated discharge while the measured discharge stays more or less stable (Fig. 5). This suggests the existence of some kind of storage volume in the Xiangxi Catchment, which is not yet accounted for in the model. Possible storage volumes slowly releasing water during the winter can be the terraced slopes or two reservoirs along Gufu River, one of the main tributaries of Xiangxi River.

The relationship between the residuals and the measured discharge is shown in Fig. 7. To improve visualization, the residuals are grouped in classes and only values within the range from -100 to $120 \mathrm{~m}^{3} \mathrm{~s}^{-1}$ are included. This range comprises 2147 out of 2192 values and thus the majority 
Q measured

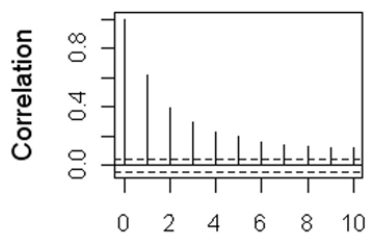

Time lag (days)

Precipitation/Q measured

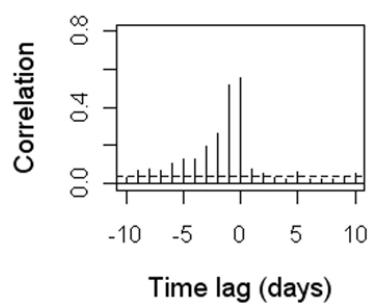

Q simulated

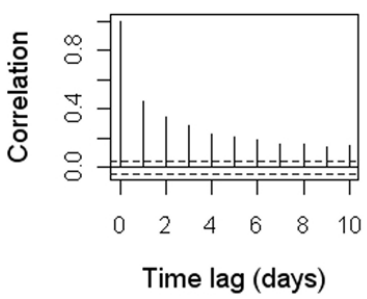

Precipitation/Q simulated

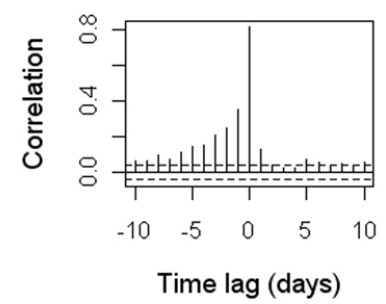

Fig. 8. Autocorrelations of measured discharge, simulated discharge and residuals and cross correlations of precipitation with measured discharge, simulated discharge and residuals.

of all residuals. Most of the residuals larger than -100 or $120 \mathrm{~m}^{3} \mathrm{~s}^{-1}$ are outliers corresponding to extreme discharge peaks. The number of values in each class is shown in Fig. 6 . The class labels in Figs. 6 and 7 indicate the lower boundary of each class. For both positive and negative residuals the number of values within each class decreases with increasing residuals (Fig. 6). Apart from this, there is a clear difference visible between negative and positive residuals. Except for a few outliers and extreme values, negative residuals, i.e. overestimations of discharge by the model, are mainly associated with relatively low measured discharges between 0 and $100 \mathrm{~m}^{3} \mathrm{~s}^{-1}$ and there is no clear trend visible. In contrast, the positive residuals show a distinct increasing trend with increasing discharge volumes. The lower the measured discharge the lower is also the underestimation of discharge by the model. Strong underestimations of discharge ranging from 60 to $120 \mathrm{~m}^{3} \mathrm{~s}^{-1}$ occur only for discharges higher than $100 \mathrm{~m}^{3} \mathrm{~s}^{-1}$. Discharges lower than $100 \mathrm{~m}^{3} \mathrm{~s}^{-1}$ are underestimated by at most $60 \mathrm{~m}^{3} \mathrm{~s}^{-1}$. There are very few outliers and extreme values of discharge and the majority of residuals are lower than $20 \mathrm{~m}^{3} \mathrm{~s}^{-1}$. The positive residuals indicate a systematic error in the simulation of discharge peaks, which might be due to an inappropriate representation of the fast runoff components.

\subsection{Analysis of auto- and cross-correlations}

The comparison of the auto-correlations of measured and simulated discharge reveals an important difference between the measured and the simulated time series (Fig. 8). For a time lag of one day, the measured discharge is stronger auto- correlated than the simulated discharge, i.e. the measured discharge on a certain day is more dependent on the discharge on the day before than the simulated discharge. This indicates that the measured discharge is influenced by slower runoff components than the simulated discharge. Therefore, the underestimation of discharge by the model is probably rather caused by too little lateral or groundwater flow than by an insufficient amount of surface runoff as assumed before. The calibration of parameters governing slow runoff components in SWAT might thus improve the simulation of peaks considerably. This assumption is supported by the crosscorrelations of measured and simulated discharge with precipitation, which show a distinct difference as well (Fig. 8). While the simulated discharge is much more dependent on the precipitation on the same day than the measured discharge, it is much less dependent on the precipitation on the previous day. This again suggests a stronger influence of fast runoff components in the simulation compared to the observation and thus a need to calibrate parameters governing slower runoff components in order to slow down the catchment's response to precipitation events in the model.

\section{Conclusions}

The study has shown that the analysis of residuals as well as auto- and cross-correlations can be valuable tools for model evaluation. While the comparison of the measured and the simulated hydrographs and the calculation of statistical criteria provide a good evaluation of the overall performance of the model, they do not allow any conclusions with regard to the key processes governing the catchment hydrology and explaining the shortcomings of simulated discharge. These have to be identified for model calibration. In regions where a sufficient amount of adequate data is available the required information can often be derived from the observed data. As this is not possible in data scarce regions, other ways of acquiring the required knowledge have to be found. In this context residual analysis as well as the analysis of auto- and cross-correlations can be used as a tool to improve understanding of key processes in a catchment.

In this paper, only a selection of possible variable interrelations is presented. A closer analysis of residuals might include the impact of further variables on residuals, e.g. evapotranspiration, surface runoff and groundwater runoff. Also, the residuals have not yet been analyzed separately for different parts of the hydrograph like the rising and the falling limb or high and low flows. Nevertheless it has been shown that residual analysis can be used to identify key processes in a catchment of interest. A more detailed analysis of residuals including more variables and evaluating specific parts of the hydrograph separately could provide further insights to the characteristics of the catchment, which have to be considered during model calibration. Especially when combined with sensitivity analysis, by which the most important model 
parameters are identified, the analysis of residuals as well as auto- and cross-correlations can be useful tools for model calibration.

Acknowledgements. The authors would like to thank the German Federal Ministry of Education and Research (BMBF, No. 03 G 0669) for funding the Sino-German Yangtze Project. Special thanks also go to the Research Centre Jülich for the project coordination and to the project partners from Tübingen and Giessen University for providing the spatial input data required by SWAT.

Edited by: R. Ludwig, K. Schulz, and M. Disse

Reviewed by: two anonymous referees

\section{References}

Abbaspour, K. C., Yang, J., Maximov, I., Siber, R., Bogner, K., Mieleitner, J., Zobrist, J., and Srinivasan, R.: Modelling hydrology and water quality in the pre-alpine/alpine Thur watershed using SWAT, J. Hydrol., 333, 413-430, 2007.

Aitken, A. P.: Assessing systematic errors in rainfall-runoff models, J. Hydrol., 20, 121-136, 1973.

Arnold, J. G. and Fohrer, N.: SWAT2000: current capabilities and research opportunities in applied watershed modeling, Hydrol. Proc., 19, 563-572, 2005.

Arnold, J. G., Srinivasan, R., Muttiah, R. S., and Williams, J. R.: Large area hydrologic modeling and assessment - part I: model development, J. Am. Water Resour. As., 34, 73-89, 1998.

Behera, S. and Panda, R. K.: Evaluation of management alternatives for an agricultural watershed in a sub-humid subtropical region using a physical process based model, Agr. Ecosyst. Environ., 113, 62-72, 2006.

Bekele, E. G. and Nicklow, J. W.: Multi-objective automatic calibration of SWAT using NSGA-II, J. Hydrol., 341, 165-176, 2007.

Cao, W., Bowden, W. B., Davie, T., and Fenemor, A.: Modelling Impacts of Land Cover Change on Critical Water Resources in the Motueka River Catchment, New Zealand, Water Resour. Manag., 23, 137-151, 2009.

Chaplot, V., Saleh, A., Jaynes, D. B., and Arnold, J.: Predicitng water, sediment and $\mathrm{NO}_{3}-\mathrm{N}$ loads under scenarios of land-use and management practices in a flat watershed, Water Air Soil Poll., 154, 271-293, 2004.

China Soil Scientific Database: http://www.soil.csdb.cn/, last access: 18 June 2010.

Eckhardt, K. and Arnold, J. G.: Automatic calibration of a distributed catchment model, J. Hydrol., 251, 103-109, 2001.

Eckhardt, K., Fohrer, N., and Frede, H.-G.: Automatic model calibration, Hydrol. Proc., 19, 651-658, 2005.

Feaster, T. D., Golden, H. E., Odom, K. R., Lowery, M. A., Conrads, P. A., and Bradley, P. M.: Simulation of streamflow in the McTier Creek watershed, South Carolina, U.S. Geological Survey Scientific Investigations Report 2010-5202, US Geological Survey, Reston, Virginia, USA, 61pp., 2010.

Fohrer, N., Möller, D., and Steiner, N.: An interdisciplinary modelling approach to evaluate the effects of land use change, Phys. Chem. Earth, 27, 655-662, 2002.

Fohrer, N., Haverkamp, S., and Frede, H.-G.: Assessment of the effects of land use patterns on hydrologic landscape functions: development of sustainable land use concepts for low mountain range areas, Hydrol. Proc., 19, 659-672, 2005.

Gassman, P. W., Reyes, M. R., Green, C. H., and Arnold, J. G.: The Soil and Water Assessment Tool: Historical Development, Applications, and Future Research Directions, T. ASABE, 50, 1211-1250, 2007.

Green, C. H. and van Griensven, A.: Autocalibration in hydrologic modeling: Using SWAT2005 in small-scale watersheds, Environ. Modell. Softw., 23, 422-434, 2008.

Guo, H., Hu, Q., and Jiang, T.: Annual and seasonal streamflow responses to climate and land-cover changes in the Poyang Lake basin, China, J. Hydrol., 355, 106-122, 2008.

Gupta, H. V., Sorooshian, S., and Yapo, P. O.: Status of automatic calibration for hydrologic models: Comparison with multilevel expert calibration, J. Hydrol. Eng., 4, 135-143, 1999.

Heuvelmans, G., Muys, B., and Feyen, J.: Evaluation of hydrological model parameter transferability for simulating the impact of land use on catchment hydrology, Phys. Chem. Earth, 29, 739747, 2004.

Hörmann, G., Köplin, N., Cai, Q., and Fohrer, N.: Using a simple model as a tool to parameterise the SWAT model of the Xinagxi river in China, Quatern. Int., 208, 116-120, 2009.

Huisman, J. A., Breuer, L., and Frede, H.-G.: Sensitivity of simulated hydrological fluxes towards changes in soil properties in response to land use change, Phys. Chem. Earth, 29, 749-758, 2004.

Jarvis, A., Reuter, H. I., Nelson, A., and Guevara, E.: Hole-filled SRTM for the globe Version 4, available from the CGIAR-CSI SRTM 90m Database (http://srtm.csi.cgiar.org (last access: 10 May 2010), 2008.

Jha, M. K., Schilling, K. E., Gassman, P. W., and Wolter, C. F.: Targeting land-use change for nitrate-nitrogen load reductions in an agricultural watershed, J. Soil Water Conserv., 65, 342-352, 2010.

Lenhart, T., Fohrer, N., and Frede, H.-G.: Effects of land use changes on the nutrient balance in mesoscale catchments, Phys. Chem. Earth, 28, 1301-1309, 2003.

Mishra, A., Kar, S., and Singh, V. P.: Prioritizing Structural Management by Quantifying the Effect of Land Use and Land Cover on Watershed Runoff and Sediment Yield, Water Resour. Manage., 21, 1899-1913, 2007.

Moriasi, D. N., Arnold, J. G., Van Liew, M. W., Bingner, R. L., Harmel, R. D., and Veith, T. L.: Model Evaluation Guidelines for Systematic Quantification of Accuracy in Watershed Simulations, T. ASABE, 50, 885-900, 2007.

Muleta, M. K. and Nicklow, J. W.: Sensitivity and uncertainty analysis coupled with automatic calibration for a distributed watershed model, J. Hydrol., 306, 127-145, 2005.

Nash, J. E. and Sutcliffe, J. V.: River Flow Forecasting Through Conceptual Models. Part I: A Discussion of Principles, J. Hydrol., 10, 282-290, 1970.

Neitsch, S. L., Arnold, J. G., Kiniry, J. R., and Williams, J. R.: Soil and Water Assessment Tool Theoretical Documentation Version 2005, Grassland, Soil and Water Research Laboratory and Blackland Research Center, Temple, Texas, USA, 2005.

Neitsch, S. L., Arnold, J. G., Kiniry, J. R., Srinivasan, R., and Williams, J. R.: Soil and Water Assessment Tool Input/Output File Documentation Version 2009, Grassland, Soil and Water Research Laboratory and Blackland Research Center, Temple, 
Texas Water Resources Institute Technical Report No. 365, College Station, Texas, USA, 2010.

Schönbrodt, S., Saumer, P., Behrens, T., Seeber, C., and Scholten, T.: Assessing the USLE Crop and Management Factor C for Soil Erosion Modeling in a Large Mountainous Watershed in Central China, J. Earth Sci., 21, 835-845, 2010.

Schönbrodt, S., Ehret, D., and Seeber, C.: Geo-risks in the Highly Dynamic Three Gorges Reservoir Ecosystem: Interactions of Soil Erosion, Mass Movements, and Land Use, Earth Surf. Proc. Land., under revision, 2012.

Schuol, J. and Abbaspour, K. C.: Calibration and uncertainty issues of a hydrological model (SWAT) applied to West Africa, Adv. Geosci., 9, 137-143, doi:10.5194/adgeo-9-137-2006, 2006.

Seeber, C., Hartmann, H., Xiang, W., and King, L.: Land Use Change and Causes in the Xiangxi Catchment, Three Gorges Area Derived from Multispectral Data, J. Earth Sci., 21, 846855,2010

Sivapalan, M., Takeuchi, K., Franks, S. W., Gupta, V. K., Karambiri, H., Lakshmi, V., Liang, X., McDonnell, J. J., Mendiondo, E. M., O'Connell, P. E., Oki, T., Pomeroy, J. W., Schertzer, D., Uhlenbrook, S., and Zehe, E.: IAHS Decade on Predictions in Ungauged Basins (PUB), 2003-2012: Shaping an exciting future for the hydrological sciences, Hydrolog. Sci. J., 48, 857-880, 2003.
Subklew, G., Ulrich, J., Fürst, L., and Höltkemeier, A.: Environmental Impacts of the Yangtze Three Gorges Project: An Overview of the Chinese-German Research Cooperation, J. Earth Sci., 21, 817-823, 2010.

Vandewiele, G. L., Xu, C.-Y., and Ni-Lar-Win: Methodology and comparative study of monthly water balance models in Belgium, China and Burma, J. Hydrol., 134, 315-347, 1992.

Van Griensven, A. and Meixner, T.: A global and efficient multiobjective auto-calibration and uncertainty estimation method for water quality catchment models, J. Hydroinform., 09.4, 277-291, 2007.

Williams, J. R.: Flood routing with variable travel time of variable storage coefficients, T. ASAE, 12, 100-103, 1969.

Xu, C.-Y.: Statistical Analysis of Parameters and Residuals of a Conceptual Water Balance Model - Methodology and Case Study, Water Resour. Manag., 15, 75-92, 2001.

Zhang, X., Srinivasan, R., and Bosch, D.: Calibration and uncertainty analysis of the SWAT model using Genetic algorithms and Bayesian Model Averaging, J. Hydrol., 374, 307-317, 2009.

Zhao, G. J., Hörmann, G., Fohrer, N., Li, H. P., Gao, J. F., and Tian, K.: Development and application of a nitrogen simulation model in a data scarce catchment in South China, Agr. Water Manage., 98, 619-631, 2011. 